\title{
Saber música (?): ciência, conhecimento e verdade
}

\section{Celso Garcia de Araújo Ramalho}

Resumo: O título é nossa questão sem resposta, uma procura, a cura da sabedoria inquiridora. O que produz ciência é tão determinante para os parâmetros de avaliação do saber musical? Como nos formamos e sabemos música? Há possibilidade de a ciência investigar esse saber e deste ser guardado por uma teoria da música? Que relação há entre música, ciência, conhecimento e verdade? Propomos pensar a teoria musical como a questão que recai sobre si mesma, isto é, o fundamento poético da memória.

Palavras-chave: Teoria da música. Educação musical. Filosofia da música. Poética. Estética.

Abstract: The title is our unanswered question, a search, the cure of inquiring wisdom. What produces science is so crucial to the evaluation parameters of musical lore? How are we molded and what do we know about music? May science investigates this wisdom, and may this wisdom be kept by a musical theory? What is the relationship among music, science, knowledge and truth? We intend to consider musical theory as a question which refers to itself, the foundation of poetic memory.

Keywords: Musical theory. Music education. Musical philosophy. Poetic. Esthetic.

A música pode ser compreendida no rol das ciências não no sentido clássico (epistêmico e técnico) e medieval (científico) ou moderno (racional e positivo), mas no sentido arcaico (memorável); a música faz o humano ciente, articulando no corpo a consciência de seus conhecimentos (co-nascimentos).

Ciência, do radical scire, no latim "saber", o sentido é "cortar através de", por isso no sânscrito chyáti, "ele corta”, e no irlandês, scían, "faca”. O latim scindere poderia ser uma variante nasalada, sendo scin-, por sci- (HECKLER; BACH; MASSING, 1984, p. 1227). A ciência corta com a faca através do real decidindo o ôntico. Conscientes, cortamos e separamos para distinguir a parte diminuindo o todo em pedaços menores. Esse corte também é rasgo, clareira, abertura, um espaço fendido, rachado do tempo ilimitado para se tornar tempo histórico. O corte permite abertura, mas pode diminuir a compreensão do todo, encurtando-o. 
A ação da ciência, para Aristóteles (2007), diz-se na palavra epistemonikós (epistemologia). Boécio distingue duas acepções inventando dois termos em latim, os neologismos scientificus, científico e scientialis (ciential?). De epistemonikós, scientialis, "próprio à ciência” e scientificus, "que produz ciência”. Nas traduções aristotélicas de Boécio, o científico é: “o resultado do silogismo epistemônico", "isto que faz saber", "que faz ciência”, "que produz o saber", o "conhecer as coisas posteriores pelas coisas anteriores", mas também "a pergunta que recai sobre a geometria, sobre a medicina", e não "que cria ciência" (BENVENISTE, 1989, p. 257). Hoje recortamos o sentido do científico preservando um único significado: "que produz ciência"; eliminamos a outra parte que diz: a questão que pergunta pelo que é "próprio à ciência". O saber da questão foi relegado à filosofia em oposição ao produzir científico da ciência. Em scientialis a ciência aproxima-se da filosofia porque pergunta sobre o que é próprio do saber; em scientificus a ciência não é capaz de pensar.

A idéia do hábito e da causalidade, a causa e conseqüência como resultado da observação de um padrão de repetição são tomadas como o que é próprio da ciência. O que produz saber é o idêntico ao modelo repetido. A ciência do recorte da carne intenciona a diminuição do conhecimento gerado pelo recorte do real no modelo científico, reduzindo as possibilidades de saber à lei do idêntico e do que já foi anteriormente comprovado.

Atrás da intenção científica, não é difícil entrever a renúncia, a confissão de impotência. Eis porque importa lembrar uma vez mais que, no domínio das ciências humanas, o desejo de compreender a realidade exige do investigador a coragem de romper com os preconceitos conscientes ou implícitos, de ter sempre presente que a ciência não se faz da perspectiva deste ou daquele particular, nem duma posição exterior e pretensamente objetiva, que supõe a eternidade das estruturas fundamentais da sociedade atual, mas da perspectiva da liberdade e da comunidade humana, a perspectiva do homem e da humanidade (GOLDMAN apud FERNANDES, 1973, p. 379). 
Para cortar, diminuir e comprovar, a ciência pouco a pouco se instrumentalizou e evoluiu nas técnicas de dissecação da natureza. O epistêmico e o técnico relacionam-se quando se pensa na ciência que produz utilizando as ferramentas da técnica. Ciência e técnica caminham juntas:

O termo técnica deriva do grego technikon. Isto designa o que pertence a technè. Este termo tem, desde o começo da língua grega, a mesma significação que epistemè - quer dizer: velar sobre uma coisa, compreendê-la. Technè quer dizer: conhecer-se em qualquer coisa, mais precisamente no facto de produzir qualquer coisa.[...] Conhecer-se é um gênero do conhecimento, de reconhecimento e de saber. O fundamento do conhecer repousa, na experiência grega, sobre o facto de abrir, de tornar manifesto o que é dado como presente (HEIDEGGER, 1995, p. 21-22).

Conhecer-se é nascer junto à terra e linguagem na cultura. A técnica produz co-nascimentos e re-co-nascimentos, manifestando a abertura, o corte profundo na carne, não para separar, simplificar ou encurtar as coisas, mas para trazê-las em presença. Consideramos a técnica como um conceito do saber que retoma a ação poética da criação. Sábio, saber, sabor, do latim sapere, "ter gosto agradável das coisas"; daí ter um bom gosto para julgamentos; antigo saxão ausebbian, "perceber"; no osco sipus, "ciente"; volsco sepu, "ciente" (HECKLER; BACH; MASSING, 1984, p. 3626). Para ter ciência e ser ciente é necessário provar ou comprovar, percebendo ou cortando. Uma ciência da música, que advém da noção do gosto, confunde a percepção do saber musical com a percepção estética do som. A estética, por sua vez, orienta-se pelo ético e étnico, muitas vezes esquecendo o poético e de-caindo na objetificação da memória como lembrança sonora, uma metonímia da música que se preserva pela percepção do órgão da escuta: a música reduzida ao som para orelhas. Um corpo que sente não é nada sem uma mente pensante, a música é a con-vivência de corpo e mente em um gesto poético pensante que cuida do que é articulado memoravelmente. A estética que não pensa a con-vivência, isto é, só aponta para uma percepção sensível, é um re-corte do real musical, portanto, uma simplificação estético-científica de 
produtos emocionais, sensitivos, sentimentais, estésicos e afetivos: representações e classificações estáticas.

O corte que a percepção em música nos provoca é um corte como abertura originária para o poético, para um dizer e mostrar projetante, ao que é próprio da linguagem, o saber e conhecer articulador de todo sentido, sentido do ser, do que é, do real.

Arte, ciência, técnica, indústria, engenharia, história, poesia, música, folclore, liturgia, epistemologia, poderíamos elaborar um dicionário com as noções que trazem à tona o saber e o conhecer. Para sermos mais sábios, mais inteligentes e superiores, "tomamos posse de algo que nos torna diferentes do que somos"; talvez seja esse o resumo da noção de superioridade fornecida pela inteligência nas culturas a partir do descontentamento com o que se tem e o que se é. Descontentes com nosso nascimento, procuramos renascer na carne e conascer na terra, saboreando os nascimentos físicos e questionando-os produtivamente. A inteligência radical aparece no saber e no conhecer, no perceber e no pensar. Nossa tentativa de superar a morte física ou prolongar a vida biológica provoca-nos a inventar uma cultura da permanência, da memória e da co-memoração da vida: nisso reside radicalmente o gesto musical.

O saber musical está na percepção e pensamento, talvez uma ciência, quando se referre à questão que recai sobre si mesma: o que é música? Assim, toda ciência é científica, e a música, como primitiva ciência, é o saber tragicômico da escatologia humana; algo de que todos os projetos humanos não podem deixar de ser, o espanto do abrir e fechar da boca e a alucinação do escutar e não escutar da orelha - perturbações que geram a fala e silêncio da língua. A ciência que questiona, escuta e silencia, pensando a questão sobre si mesma, guarda na excelência sua música, sua cantiga, seu réquiem. O primitivo sentido do nascer cultural e o último a ser esquecido: a escuta. Não é apenas a audição, o ouvir pelos canais auriculares, mas a experiência de saber pela escuta; escutar de novo; ter que escutar incessantemente para compreender e conhecer mundo; aperceberse da coisa; ser, apreender e aperceber; estar na percepção como quem é possuído pelo acontecer do aperceber-se infinitamente na finitude. O saber musical configura-se como tal num nascer da cultura, de novo dizer o mundo, de 
novo auscultar o mundo para ser e pensar. A crise crítica das línguas está na consolidação do saber musical e reconhecimento em linguagem como escuta radical, possibilitando nosso próprio nascimento em projeto humano e inumano.

Na viagem e viragem etimológica distinguimos ao menos dois modos de conhecer, o analítico e o sintético, melhor dizer um que corta (scire e escat-) e depois junta (som-, de soma, sem-, de sema, sempre, sim-, de similar, juntado num só) e outro que é todo um, unidade, indivisível, enigmático, sagrado, mágico, língua musical, mendh-, memória, que apreende verdade - o nãocortado. No coito do poeta-músico estarão os fundamentos de uma teoria da linguagem historicamente humana - condições de nascimento das culturas. De lamber memórias abrindo a boca, movendo a língua, balbuciando, falando, laudando num deslize os dentes talham o lábio. O néscio, de não cortar (non scire), ao cortar a carne, ciente agora está do mordaz sarcasmo. Saboreia no corte o sangue, de tanto sangrar no saber glosa hemático merece a morte. Sacrifica-se na faina pensando as feridas e aplica punições aos violadores da lei para preservar as regras do culto. A pena por ter cortado o que não podia ser cortado, o íntegro (sagrado), é a consciência da morte. O corte letal transpõe o imolado de um estado profano da vida ao estado que o reconduzirá ao tempo divino. Aprendendo a ciência mortal o projeto humano de vida reconhece em si mesmo a unidade a partir da música, rememorando a sabedoria imorredoura.

Reconhece-se no pensamento tragicômico a residência e resistência da força de toda cultura, performatizando-se em memória criativa, no gesto inaugural dos nascimentos extáticos e oníricos da percepção ódica. O tempo da ode leva-nos ao caminho provisório, não visível e invisível, visionário e antevisto, histórico como sabedoria dos acontecimentos, dramático como a orgia mórbida, científico como conhecimento da questão - nascimento do entusiasmo de perquirir e saber o não ser. O saber próprio do músico auscultador (aquele que escuta e pensa) vigora no agir que deixa sempre um lugar para o não racional para que a questão sobreviva como questão.

No recorte científico, a ciência do som é possível e a ciência da música incompatível. O som quer se juntar a outros sons, a outros pedaços musicais para fazer sentido como música. O som é um pedaço que se recortou da música, e na 
soma dos sons, das partes, não se faz o todo musical. A análise do aspecto sonoro de uma canção a despedaça, deixando-a em frangalhos. Uma ciência científica da música é uma cacofonia pleonástica, porque o musical e o científico são saberes radicalmente diferentes: um inaugura a abertura para um tempo produtivo, o outro reproduz o tempo cortado. Ao abrir a cultura para a produção, a música mostra o que é verdadeiro.

O musical é o verdadeiro porque nos faz não esquecer; o poeta sabe porque sua sabedoria própria é não-esquecimento (não esquecer pelo grego alétheia, verdade), o poeta-músico é um aletófilo. A verdade do saber musical pode ser entendida como algo não cortado, não separado, para depois ser juntado, por isso não esquecido. O musical é o inviolável escutar são, sadio, sem defeito, sem cortes, a carne da orelha não separada do pensamento do corpo. A memória está sã e salva na ausculta musical - a escuta questionadora. Esse é o tipo, modelo e exemplo (type) para as artes, ciências e técnicas, o tempo da música que não separa a escuta da memória.

No corte realizamos a operação de cortar para se obter algo que sem o corte não seria possível; penetrando por meio da incisão, eliminamos o obstáculo do todo, desfazendo o enigma, desenlaçamos mente e corpo, alma e carne. Ao cortar, sabemos mais sobre a coisa cortada, e de tanto cortar encurtamos o todo na atomização de uma ciência do corte; do resultado deste corte, o ciente, o consciente, a consciência, o inconsciente e a esquizofrenia - esquizo-, no latim, scindere, "separar, cortar" (HECKLER; BACH; MASSING, 1984, p. 1405). A ciência do recorte se sagra esquizofrenia da religião, da alma cortada e dividida em corpo e mente; uma religião esquizóide separa a poética dos mortais e imortais, da natureza e cultura que se autoproduz na habitação humana, num corte que mata aniquilando a memória. Nem toda ciência é esquizofrenia da cultura, talvez apenas essa qualidade esteja presente no que comumente denominamos Cultura Ocidental, e em uma certa parte do ocidente; este ocidente que gera seu saber pelo corte do real na linha dicotômica, separando o que é do que não é em uma ciência, uma filosofia, uma música, uma cultura consciente de suas razões esquizóides. Seria inútil tentar localizar esse ocidente geograficamente: vivemos hoje um estado pretensamente globalizado; assim, a esquizofrenia está no 
método, ou quem sabe no sistema de ensino, no governo, na propaganda, nos veículos de comunicação, na ideologia publicada, na psique, na utilização da tecnologia, na economia, no trabalho, na língua; quem saberá onde mora esse ato do ser humano dividido? Estará na mente esquizofrênica de cada um?

A compleição rítmica da forma musical não sofre a patologia esquizofrênica do corte separador; porque, ao ser cortada, a música desfaz-se no corte, como a esfera, o ovo, o círculo, o óptico e ótico cortados convertem-se em semimúsica, semiovo, semicírculo, semióptico e semiótico. O saber musical não é decomponível, não pode ser cortado, sob o risco de ser destruído, converter-se em não-saber, perder seu caráter de sabedoria por ter sido desfeito no corte epistemológico. Daí o rebaixamento do poeta-músico? Por que detém um saber hermético e enigmático? O segredo incontrolável não poderá ser descoberto na obra deste ou daquele autor; não é pela análise do mundo que chegamos a perceber o enigma dos mundos. O enigmático é o verdadeiro conhecimento ciential (saber próprio à música), que não reside na objetividade do mundo, mas em como e por que o mundo é mundo, isto é, no que possibilita à humanidade ser. O enigma mora onde a humanidade também mora; a morada extraordinária e ecológica: linguagem.

Na impossibilidade de objetivação, coisificação, subjetivação e generalização para que a música seja manipulada, passada de ouvido a ouvido, de mão em mão, de olho a olho, como um "tratado científico sobre as plantas", como um instrumento agrimensor, ou como uma regra ditada para ser aplicada na melhora da colheita; concluímos que a música não é uma ciência do saber musical que faz ciência no corte epistemológico, mas no sentido gignológico do nascer, da nação, saber como co-nascimento, conhecer como no sânscrito jánati, ele nasce, conhecer música é nascer inteiramente e interiormente (HECKLER; BACH; MASSING, 1984, p. 2864). A questão para o pensamento é a história dos nascimentos e não o corte e recorte.

O conhecimento como co-nascimento na cultura é dito também na palavra história. Do latim pelo grego, história, derivado do adjetivo histor, que sabe (conhecimento, sabedoria); de eidenai, do indo-europeu, *weid (do grego eidos, forma), relacionado com o sânscrito, Vedas, conhecimento; alemão, wissen 
e wisdom, no inglês, sabedoria (HECKLER; BACH; MASSING, 1984, p. 1629). A história do conhecimento fala a língua musical dos povos como projeto universal de nascimento do mundo. Canções, augúrios, ritos, danças, gestos da fala e do corpo, êxtases, delírios, fábulas e sátiras guardam a sabedoria que não cabe nos livros de história. A história da música é a história do saber musical de toda cultura. A história da música é a ciência como conhecimento geral do mundo, a sabedoria da forma, no testemunho das vivências e falências musicais da língua.

O projeto cartesiano de uma ciência geral, de saber universal aplicável a qualquer disciplina, poderia ser escrito no primeiro livro de Descartes, o "Compendio Musicae", não fosse o "cogito" a agitação apressada de ouvir a cultura racionalmente. Descartes poderia descartar todas as meditações e assumir energicamente com grito inebriado a musicalidade. A música geral compreenderia o quão musical é o direito, a química, a física, a matemática, a história e qualquer outra disciplina que faz ciência, e ainda as artes, filhas e irmãs da música. Na auscultação musical do que faz ciência, colocamo-nos na questão de saber música pensando e auscultando corporalmente a cultura.

A cultura globalizada seduz por um processo de mediocrização das culturas, convertendo o significado de re-colhimento em meio ou média ou mediação, apesar desse cenário global tenebroso, vivenciando e co-nascendo a cultura como relação concreta com o mundo abrimos possibilidades de rasgar as camadas de empoeiramento da língua que obscurecem a linguagem. A unidade possível de se estabelecer entre as diferentes culturas e a cultura brasileira ressalta o que existe de próprio em cada cultura, só assim é que encontraremos a unidades dos diferentes, nesse jogo de estranhamento aprofundaremos nossa reflexão sobre a realidade do outro e de nossa própria realidade. As tradições musicais brasileiras só poderão ser preservadas se forem atualizadas, isto é, para que uma tradição sobreviva é fundamental a inovação (FERNANDES, 2009). A inovação é essencialmente o imaginar, o criar como invenção da cultura, não como uma reprodução de certas práticas culturais apenas, como se a cultura fosse uma operação de repetição mecânica de uma máquina. O real é sempre o mesmo e outro, isto é, sempre diferença (DELEUZE, 2000); nesse diferente se concretiza identidade como unidade. 
Porque somos diferentes uns dos outros é que podemos estabelecer intercâmbio de identidades como unidade de nossas atuações, agenciamentos e relações culturais. Não para nos tornamos iguais, isso não é nem desejável e nem possível, mas para cada vez afirmarmos mais nossas diferenças, isto é, o que nos torna verdadeiramente o que e quem somos como humanos habitantes de um universo cultural, assim nos distinguimos e podemos ser estranhamente juntos unidade na diferença entre ser ou não brasileiro: eis a sabedoria e conhecimento articuladores de sentido memorável na salvaguarda de nossas tradições.

As matrizes deixadas nos pedaços de mundo habitados por povos ibéricos foram, dentro da dinâmica histórica de nosso país, abandonadas, isto é, entregues, ao imaginar livre das dominações institucionais, esse abandono e o não lugar do dono, “aufgabe”, em alemão, "nedlaggling”, terra dada a ninguém em sueco. Experiências de mundo próprias de cada cultura e nomeações, diferentes para mostrar e dizer o mesmo. A música projeta um dimensionamento de mundo que nos lança para fora das medidas impostas pelas instituições de controle e poder; a música é um saber que se mede por si mesmo, um saber mítico como conhecimento de mundo, isto é, para saber a música de um povo somos convidados a conhecer a cultura desse povo, somos obrigados a co-nascer, nascer junto à cultura desse povo, e nesse estar junto con-vivemos com o entrecruzamento, o estar com o outro, junto à diferença, con-viver com o estranhamento da alteridade, esse é um aprendizado profundo das trocas entre culturas linguísticas e musicais diferentes: saber bardo.

Se a música é modo mítico de conhecer, podemos experenciar a radical diferença de habitar a cultura como se estivéssemos em um momento de criação da própria cultura brasileira, tamanha é a riqueza de sentidos que a obra de arte pode proporcionar para o ser humano num exercício de abertura, corte, rasgo, abandono, entrega ao estranhamento. Oportunidades singulares de desdobramento das influências mútuas entre as matrizes europeias, africanas, latino-americanas, indígenas, para citar apenas as referências mais gerais. Investigando profundamente encontraremos minúcias de culturas esquecidas e ocultadas pela média superficial da referenciação esteriotipada por ausência de pesquisas e representações não pensadas. Propomos pensar a cultura brasileira 
numa mútua referenciação ao próprio sentido radical de cultura que é cultivar, cuidar e habitar, somente a criação artística no sentido grego de poiseis ou no latim producere, no germânico dichtung, dizer projetante, ou português "produzir", permite-nos trazer adiante, conduzir à presença o que antes não havia, como instauração de mundos.

As línguas são os diferentes modos de recolher em nomeações as culturas, e, como nos diz Nietzsche, a música mostra-nos como muitas coisas que não podem ser ditas pela língua ou de nenhum outro modo pela cultura são dizeres que só podem ser ditos e mostrados como dizeres musicais. A música recolhe de uma forma própria a poesia da língua. Aprender as experiências musicais significa aproximar-se de forma poética da poesia essencial da cultura.

Mas há ainda uma prevalência da cultura da ciência que domina os bancos escolares e acadêmicos, pois somos disciplinados pela técnica instrumentalizadora e pela representação da unidade da cultura como igualdade de características. O que pode essa disciplinarização do saber e conhecer por meio da ciência do re-corte e abstração do real? Pode muito pouco que cada pedaço de partes juntadas oferece.

A ciência disciplinar acredita que ao juntar os pedaços desmembrados reconstituirá o todo do corpo novamente, mas não vê que cada disciplina toma para si em seu recorte apenas o braço, o dedo, o cérebro, a orelha, o coração, o rim; um pedaço de carne do corpo. O pré-fixo pretende restituir a parte recortada, mas mantém no pós-fixo o corte presente. Juntando-se apenas um rim e uma orelha, numa relação multidisciplinar, as outras partes desmembradas continuarão ausentes e se manterá a visão recortada nesse corpo parcialmente juntado. A disciplina dispensa prefixos pois não trata o conhecimento numa relação necessariamente epistemológica. Disciplinar, discípulo e disco estão relacionados na formação da Paideia humana.

A etimologia de disciplina é obscura, no latim discere (disc-), "aprender"; relaciona-se ao sentido original de "crer"(HECKLER; BACH; MASSING, 1984, p. 1508). Os romanos não separavam os étimos de discípulo e disco, como em edisco "aprender a fundo ou de cor", predisco "aprender de cabo a rabo" e praedisco "aprender antecipadamente" (HOUAISS, 2001). Em docere, ensinar, e 
discere, aprender, temos as oposições necessárias para disciplina; o grego mantháno diz ao mesmo tempo aprender e ensinar (LIDDELL; SCOTT, 1996, p. 1078-9), pelo lexema indo-europeu *mendh, também música (HECKLER; BACH; MASSING, 1984, p. 2852). Di-sci-plina, poderia ser compreendida na decomposição de di-, "negar, dissuadir, contrariamente, diferenciar, superar, atravessar, consumar", sci-, "saber, decidir, cortar"; -pl- (-pul-) plicare, "desdobrar"; desdobrando o saber, lança-se contrariamente discípulo e disciplinador. O conhecimento é possível quando cremos na tensão disciplinadora entre ensinar e aprender. Aprendendo a conhecer a música ensinamos a narrativa da memória (de narrar nascimentos, gnarus, “fazer conhecer") (Id. ibid., p. 2881).

Música é originariamente contra qualquer tipo de inter-trans-pluri-multidisciplinaridade. Se música é unidade da memória, quando a dividimos pela ótica dos cortes disciplinares já não podemos mais encontrar o fenômeno da unidade, mas tão somente os olhares disciplinadores do todo, as partes que arvoram para si o direito de legislar sobre o que o todo é: pelo viés da história, a música é a representação de uma época; pelo viés da matemática, a música é a arte da mensuração de alturas e durações; e assim seguimos sem compreender a unidade. O fragmento 50 de Heráclito (1999, p. 71) nos dá a dimensão da unidade musical: "Auscultando não a mim mas o Logos, é sábio concordar que tudo é um". O concordar heraclítico é a harmonia dos movimentos contrários, dito no fragmento 51 e rearranjado no fragmento 60: "Caminho: para cima, para baixo, um e o mesmo" (HERÁCLITO, 1999, p. 75). O caminho percorrido pelo fenômeno musical, quando é apenas medido e representado pelas ações disciplinadoras das ciências da lógica e do cálculo, passa a ser conservado nos elementos e estruturas audíveis e visíveis descritas pelos esquemas de suporte e objetificação do musical, sem comprometimento com a escuta para linguagem, perde seu saber e se desloda da dimensão poética que é o lugar em que podemos medir música pelo próprio das “coisas musicais”. Apontamos para a dimensão poética, criativa e fenomênica como lugar de pensar e cuidar da música.

História e matemática estão recolhidas nas articulações do músico. As disciplinas são mais artísticas quando se aproximam da música, articulando-se musicalmente. O músico só faz memória porque escuta linguagem. Quando 
fazemos a pergunta que recai sobre nós mesmos, abolimos toda sensação estética, noção subjetiva, objetiva e adjetiva, dando ouvidos à linguagem em nós. Somente numa ausculta musical é possível retroceder ao sentido da música em todas as artes. Pensando a sabedoria da arte e poética do corpo, escutamos a fala da linguagem. Música orienta a escuta para o sentido da linguagem, preservando a essência criativa das línguas; um saber concreto que, ao narrar a coisa no canto, apreende o que pode ser apercebido pela musicalidade corpórea num jogo de símbolo e reflexo entre humanos e terra. A musicalidade da narrativa traz a força vindoura concretizada pelo poder imaginativo na performance da fala musical. Aprendemos e ensinamos a perceber, ser e pensar no lorotar (learn) e saborear (savour) do saber no tempo musical.

As ações de saborear e saber estão relacionadas ao modo como fazemos as coisas, com gosto ou sem gosto, com saber ou sem saber. Para emitir um juízo de gosto, temos que provar o bom e o ruim, o belo e o feio, o claro e o escuro, o sonoro e o silencioso, o consonante e dissonante, o falso e o verdadeiro; na contradição está a sabedoria do julgamento, nos contrários reside a força da unidade de todas as coisas. O juízo racional decide-se na certeza comprovada pelo hábito ou calculada previamente por uma fórmula. No juízo musical não há juiz, julgamento ou júri; a lei é o saber da escuta e a forma é a performance sempre atual, não há possibilidade de prejuízos ou pós-julgamentos, se estamos na percepção da música somos músicos auscultadores de nossa performance. A lei musical é escutar a linguagem na canção e dançar conforme a música - sabedoria que ensina a lamber verdades e a se alucinar apreendendo no tempo da escuta o saber da imortalidade humana.

\section{Referências}

ARISTÓTELES. Tópicos. Lisboa: INCM, 2007.

BENVENISTE, Émile. Problemas de lingüística geral II. Campinas: Pontes, 1989.

DELEUZE, Gilles. Diferença e repetição. São Paulo: Relógio D’Água, 2000. 
FERNANDES, Florestan. A investigação etnológica no Brasil e outros ensaios. São Paulo: Global, 2009.

GOLDMAN, Lucien. In: FERNANDES, Florestan. Comunidade e sociedade: leituras sobre problemas conceituais, metodológicos e de aplicação. São Paulo: Nacional/ USP, 1973.

HECKLER, Evaldo; BACK, Sebald; MASSING, Egon. Dicionário morfológico da língua portuguesa. V vols. São Leopoldo: Unisinos, 1984.

HEIDEGGER, Martin. Língua de tradição e língua técnica. Lisboa: Passagens, 1995.

HERÁCLITO in: OS PENSADORES ORIGINÁRIOS. Petrópolis: Vozes, 1999.

HOUAISS, Antônio. Dicionário eletrônico Houaiss da língua portuguesa 1.0. Rio de Janeiro: Objetiva, 2001.

LIDDELL, Henry George; SCOTT, Robert. A Greek-English lexicon. Oxford: Clarendon Press, 1996. 